\title{
Analisis Kelayakan Agroindustri Pengolahan Salak Ud Salacca Di Desa Aek Nabara Kecamatan Angkola Barat Kabupaten Tapanuli Selatan Provinsi Sumatera Utara
}

\author{
(Feasibility Analysis Of Salak Pocessing Agroindustry Salacca Trading Business In \\ Aek Nabara Village, West Angkola District, South Tapanuli Regency, North Sumatera \\ Province)
}

\author{
Laily Arfah Ritonga ${ }^{1}$, Irwan ${ }^{1}$, Lukman Hakim ${ }^{1 *}$ \\ ${ }^{1}$ Program Studi Agribisnis, Fakultas Pertanian, Universitas Syiah Kuala \\ *Corresponding author: lukman.hakim.sp.mp@unsyiah.ac.id
}

\begin{abstract}
Abstrak. UD Salacca merupakan salah satu unit usaha yang bergerak dalam pengolahan makanan dan minuman yang terbuat dari salak seperti dodol, keripik, sirup, kurma dan lainnya. Tujuan penelitian ini menganalisis teknik pengolahan salak, keuntungan, kelayakan, saluran pemasaran, margin pemasaran dan efesiensi pemasaran dari UD Salacca. Metode penelitian yang digunakan yaitu analisis keuntungan, analisis kelayakan usaha analisis margin dan analisis efesiensi pemasaran. Hasil penelitian menunjukkan pengolahan produk UD Salacca dimulai dari proses pengupasan kulit salak, pencucian buah salak, dan pemisahan biji dengan daging salak selanjutkanya proses perebusan daging salak, daging salak digiling, pemasakan daging salak dengan pencampuran bahanbahan yang diperlukan, selanjutnya pengemasan. UD Salacca memiliki keuntungan sebesar Rp 240.263.152,- per tahunnya. Revenue Cost Ratio (R/C Ratio) sebesar 1,44, BEP Produksi sebesar $7.074 \mathrm{~kg}$ dan BEP harga sebesar Rp 48.766,- dan Return on Investment (ROI) sebesar $44 \%$. Disimpulkan bahwa UD Salacca menguntungkan dan layak dijalankan. UD Salacca mempunyai dua saluran pemasaran yaitu: saluran pemasaran 1 (UD Salacca Konsumen), dan saluran pemasaran II (UD Salacca - Pengecer - Konsumen). Saluran pemasaran I mimiliki margin sebesar Rp 58.545,- pada saluran pemasaran II UD Salacca memiliki margin sebesar Rp 50.064,pengecer memiliki margin sebesar Rp 8.481,-.Saluran pemasaran I adalah yang paling efesien dengan persentase sebesar $35 \%$.
\end{abstract}

Kata kunci : Kalayakan Usaha, Efesiensi Pemasaran, Agroindustri Pengolahan Salak

\begin{abstract}
Salacca trading business is one of the business units engaged in the processing of food and beverages made from salak such as lunkhead, chips, syrup, dates and others. The purpose of this study is to analyze salak processing techniques, profits, feasibility, marketing channels, marketing margins and marketing efficiency of the Salacca trading business. The research method used is profit analysis, business feasibility analysis, margin analysis and marketing efficiency analysis. The results showed that the processing of Salacca trading business products started from the process of peeling the skin of the salak, washing the salak fruit, and separating the seeds from the salak meat, then the process of boiling the salak meat, grinding the salak. meat, cooking salak meat by mixing the necessary ingredients, then packaged. The Salacca trading business has a profit of Rp 240,263,152 per year. Revenue Cost Ratio (R/C Ratio) of 1.44, BEP of Production 7,074 kg and BEP of price of Rp 48,766, - and Return on Investment (ROI) of 44\%. It is concluded that the Salak Trading Business is profitable and feasible to run. The Salacca trading business has two marketing channels, that is: marketing channel 1 (Salacca trading business - consumer), and marketing channel II (Salacca trading business - retailer consumer). Marketing channel I has a margin of Rp 58,545,- in marketing channel II Salacca trading business have a margin of $\mathrm{Rp} 50,064,-$ retailers have a margin of $\mathrm{Rp} \mathrm{8,481,-.} \mathrm{Marketing} \mathrm{channel} \mathrm{I} \mathrm{is} \mathrm{the} \mathrm{most} \mathrm{efficient}$ with a percentage of $35 \%$.
\end{abstract}

Keywords: Feasibility, Marketing Efficiency, Salak Processing agroindustry

\section{PENDAHULUAN}

Salak salah satu merupakan komoditas pertanian yang didorong pemerintah untuk kegiatan ekspor. salak Indonesia telah menembus 29 negara di dunia tanpa mengalami hambatan karena memenuhi standar yang disyaratkan oleh negara tujuan. Data Statistik Pertanian Hortikultural (SPH) menunjukkan bahwa terdapat lima komuditas yang memberikan konstribusi besar terhadap produksi buah di Indonesia yaitu: pisang, mangga, 
nanas, jeruk siam/kapok dan salak. Produksi salak menempati urutan kelima dengan produksi sebesar 1.118.953,00 ton atau sekitar 5,65 persen terhadap total produksi buah nasional.

Tedapat beberapa sentra produksi salak terbesar di Indonesia dan Sumatera Utara merupakan satu-satunya sentra produksi salak terbesar dengan produksi tertinggi terjadi pada tahun 2019 yaitu sebesar 235.506,00 ton (BPS Indonesia , 2020). Salah satu yang berpotensi menjadi komoditi unggulan di Sumatra Utara dalam sektor hortikultura adalah buah salak. Penyumbang hasil produksi salak tersbesar di Sumatra Utara yaitu Kabupaten Tapanuli Selatan yang menghasilkan salak dengan tampilan yang menggiurkan, berukuran besar, kulit tebal, rasa yang manis dan sedikit sepat.

Kabupaten Tapanuli Selatan terbagi menjadi beberapa kecamatan, dimana setiap kecamatan rata-rata merupakan penghasil salak. Kecamatan Angkola Barat merupakan daerah yang memilki luas panen dan produksi salak terbesar dibandingkan kecamatan lainnya yaitu sebesar 18.258,35 ha dan produksi sebesar 192.501,40 ton (Dinas Pertanian Kab. Tapanuli Selatan, 2020). Melimpahnya hasil salak tersebut membuat petani bingung untuk menjual salaknya bahkan sering petani tidak memanen buah salak karna harga yang sangat rendah apalagi pada saat panen serempak terjadi. Melihat potensi yang ada maka diperlukan agroindustri pengolahan yang memanfaatkan peluang tersebut. Agroindustri merupakan subsistem agribisnis yang memproses bahan-bahan hasil pertanian menjadi barang jadi yang dapat dikonsumsi dan dapat digunakan sebagai bahan industri lainnya (Kusnandar et al. 2010).

Strategi dari para petani adalah melakukan pengolahan terhadap buah salak dan kemudian dapat dijual dengan sistem kemasan sehingga pemasarannya lebih luas dan bisa di ekspor ke luar negeri. Dengan pemasaran yang lebih luas akan dapat memenuhi kebutuhan dan keinginan petani dengan menciptakan suatu produk, menawarkan, dan bertukar produk yang mempunyai nilai tambah dengan pihak lain (Kotler dan Amstrong, 2000). Menurut Anarsis (2003) upaya yang dapat dilakukan adalah masa simpan buah harus diperpanjang sehingga miningkatkan nilai tambah dan sekaligus meningkatkan nilai ekonomisnya yaitu dengan proses pengolahan dan pengawetan buah salak segar seperti olahan dodol, wajit, manisan, asinan dan keripik salak. Hasil pengolahan salak tersebut memiliki nilai tambah ganda yaitu memperpanjang waktu simpan dan meningkatkan nilai jualnya. Maka dari hal tersebut dibentuklah sebuah agroindustri pengolahan salak yaitu UD Salacca.

UD Salacca merupakan salah satu unit usaha yang bergerak dalam pengolahan makanan dan minuman yang terbuat dari salak seperti dodol, keripik, sirup, kurma dan lainnya. UD Salacca selain menjual produk olahan jadi salak juga sebagai tempat pelatihan pengolahan buah, tempat penelitian, tempat berekreasi dengan tersedianya kebun salak siap petik sendiri yang berada langsung. UD Salacca ini konsisten mengembangkan produksi dari beberapa produknya dan meningkatkan kualitas dari produk agar masyarakat lebih menyukainya. Sehingga akan meningkatkan jumlah penjualan dari setiap produk yang telah di produksi.

Agroindustri pengolahan salak ini cukup berpotensi dan layak untuk dikembangkan. Masyarakat Indonesia menyukai buah ini sehingga konsumsi salak untuk pasaran lokal cukup tinggi. Bahkan meskipun dalam volume yang masih relatif kecil, buat tropis ini sudah menembus pasar luar negeri. Oleh pemerintah, salak ditetapkan sebagai salah satu komoditas yang mendapat prioritas untuk ditingkatkan nilai ekspornya (Yustina dan Farry, 1993).Tujuan dari penelitian ini adalah untuk menganalisis teknik pengolahan salak UD Salacca, untuk menganalisis keuntungan dan kelayakan usaha agroindustri pengolahan Salak UD Salacca dan untuk menganalisis saluran pemasaran, margin pemasaran dan efesiensi pemasaran agroindustri pengolahan salak UD Salacca. 


\section{METODE PENELITIAN}

Penelitian ini dilakukan pada agroindustri pengolahan Salak UD Salacca, Desa Aek Nabara Kecamatan Angkola Barat, Kabupaten Tapanuli Selatan, Propinsi Sumatera Utara. Pemilihan lokasi secara sengaja (Purposive Sampling) dengan mempertimbangkan bahwa agroindustri pengolahan salak UD Salacca merupakan salah satu dari beberapa agroindustri yang bergerak dalam bidang pengolahan salak di Tapanuli Selatan. Penelitian dilaksanakan pada bulan Oktober 2020-Februari 2021.

Objek penelitian ini adalah agroindustri pengolahan Salak UD Salacca, Desa Aek Nabara, Kecamatan Angkola Barat, Kabupaten Tapanuli Selatan, Provinsi Sumatera Utara. Adapun ruang lingkup penelitian ini adalah untuk menganalisis prospek agroindustri pengolahan salak UD Salacca di desa Aek Nabara Kecamatan Angkola Barat Kabupaten Tapanuli Selatan, Sumatera Utara.

Data yang digunakan dalam penelitian ini adalah data primer diperoleh dengan cara observasi dan wawancara. Data sekunder diperoleh dari laporan tahunan perusahaan, Badan Pusan Statistik (BPS), penelitian terdahulu, buku, serta bahan kuliah serta sumber data lainnya.

Metode penelitian ini adalah studi kasus (Case Study) yang merupakan bagian dari metode kualitatif yang hendak mendalami suatu kasus tertentu secara mendalam dengan melibatkan pengumpulan beraneka sumber informasi untuk menganalisis gambaran umum perusahaan dan digunakan analisis kuantitatif untuk menganalisis kelayakan agroindustri pengolahan salak UD Salacca. Adapun analisis data yang digunakan sebagai berikut :

\section{Analisis Keuntungan}

\section{a. Biaya Produksi}

Biaya produksi adalah semua pengeluaran ekonomis yang harus dikeluarkan untuk memproduksi suatu barang. Adapun rumus untuk menghitung biaya produksi (Soekartawi, 2006).

$$
\mathrm{TC}=\mathrm{TFC}+\mathrm{TVC} \ldots \ldots \ldots . .(\text { Soekartawi, 2006) }
$$

Keterangan : $\mathrm{TC}=$ Total biaya dari UD Salacca $(\mathrm{Rp})$

TFC $=$ Total biaya tetap dari UD Salacca $(\mathrm{Rp})$

$\mathrm{TV}=$ Total biaya variabel dari UD Salacca $(\mathrm{Rp})$

b.Penerimaan

Menurut Soekartawi (2006) penerimaan adalah perkalian antara produksi dengan harga jual. Pernyataan ini secara matematis dapat ditulis sebagai berikut:

$$
\mathrm{TR}=\mathrm{Y} \times \mathrm{Py} \ldots \ldots \ldots . . .(\text { Soekartawi, 2006) }
$$

Keterangan $: \mathrm{TR}=$ Total Revenue $($ Total penerimaan) penjualan $(\mathrm{Rp})$

$\mathrm{Y}=$ Produksi yang diperoleh dalam pembuatan $(\mathrm{Kg})$

Py = Harga jual $(\mathrm{Rp} / \mathrm{Kg})$

Kriteria yang dipakai adalah:

Bila TR $>$ TC maka agroindustri pengolahan salak UD Salacca menguntungkan

Bila TR $<$ TC maka agroindustri pengolahan salak UD Salacca tidak menguntungkan 
b. Keuntungan

Keuntungan usaha merupakan pengurangan pendapatan total dengan biaya total dari agroindusri pengolahan salak UD Salacaca. Menurut Soekartawi (2006) Perhitungan keuntungan usaha dapat dirumuskan sebagai berikut:

$$
\pi=\mathrm{TR}-\mathrm{TC} \ldots \ldots \ldots(\text { Soekartawi, 2006) }
$$

$$
\text { Keterangan : } \begin{aligned}
\pi & =\text { Keuntungan usaha salak }(\mathrm{Rp}) \\
\mathrm{TR} & =\text { Total Revenue }(\text { Total Penerimaan) }(\mathrm{Rp}) \\
\mathrm{TC} & =\text { Total Cost }(\text { Total Biaya) }(\mathrm{Rp})
\end{aligned}
$$

\section{Analisis Kelayakan Usaha}

a. Revenue Cost Ratio (R/C Ratio)

Revenue Cost Ratio (R/C Ratio) merupakan perbandingan ratio antara total penerimaan (Total Revenue) dengan Total biaya (Total Cost). R/C ratio dirumuskan sebagai berikut (Soekartawi, 2001) :

$$
\mathrm{R} / \mathrm{C}=\frac{\mathrm{TR}}{\mathrm{TC}} \ldots \ldots \ldots(\text { Soekartawi, 2001) }
$$

Keterangan : $\quad \mathrm{TR}=$ Total Penerimaan $($ Total Revenue $)(\mathrm{Rp})$

$$
\mathrm{TC}=\text { Total biaya }(\text { Total } \text { Cost })(\mathrm{Rp})
$$

Kriteria yang dipakai adalah :

$\mathrm{R} / \mathrm{C}>1=\quad$ UD Salacca layak untuk dikembangkan

$\mathrm{R} / \mathrm{C}=1=\quad$ UD Salacca titik impas (Break Event Point)

$\mathrm{R} / \mathrm{C}<1=\quad$ UD Salacca tidak layak untuk dikembangkan

\section{b. Break Event Point (BEP)}

Break Event Point merupakan analisis untuk menentukan dan mencari jumlah barang atau jasa yang harus dijual kepada konsumen pada harga tertentu untuk menutupi biaya-biaya yang timbul serta mendapatkan keuntungan/profit. Ada dua jenis BEP, yaitu BEP produksi dan BEP harga yang dirumuskan sebagai berikut (Soekartawi, 2006) :

$$
\begin{aligned}
\text { BEP Produksi }(\mathrm{Kg}) & =\frac{\text { Total Biaya }}{\text { Harga penjualan } \ldots \ldots . . .(\text { Soekartawi, 2006) }} \\
\text { BEP Harga }(\mathrm{Rp} & =\frac{\text { Total Biaya }}{\text { Total Produski }} \ldots \ldots \ldots . . .(\text { Soekartawi, 2006) }
\end{aligned}
$$

Kriteria yang dipakai adalah :

BEP Produksi < Jumlah Produski = Usaha berada pada posisi menguntungkan

BEP Produksi $=$ Jumlah Produski $=$ Usaha berada pada posisi titik impas

BEP Produksi $>$ Jumlah Produksi = Usaha Berada pada posisi yang tidak menguntungkan

\section{c. Return on Investment (ROI)}

Return on Investment (ROI) atau return on asset merupakan rasio yang menunjukkan hasil (return) atas jumlah aktiva yang digunakan dalam perusahaan. Menurut Kasmir dann Jakfar (2015), rumus untuk mencari Return on Investment dapat digunakan sebagai berikut: 


$$
\text { ROI }=\frac{\text { Laba bersih setelah bunga dan pajak }}{\text { Total aset }} \ldots \ldots \ldots \text { (Kasmir dan Jakfar,2015) }
$$

\section{Analisis Margin Pemasaran dan Efesiensi Pemasaran}

a. Margin Pemasaran

Menurut Soekartawi (2002) margin pemasaran merupakan perbedaan harga ditingkat petani dengan tingkat konsumen, untuk mengetahui besarnya margin pada masing-masing lemabaga pemasaran yang terlibat maka digunakan rumus berikut :

a) Margin tiap lembaga pemasaran UD Salacca:

$$
\text { Mp}=\operatorname{Pr}-\operatorname{Pf} . \ldots \ldots \ldots(\text { Soekartawi,2002) }
$$

$$
\begin{array}{ll}
\text { Keterangan : } & \mathrm{Mp}=\text { Margin pemasaran }(\mathrm{Rp} / \mathrm{kg}) \\
& \mathrm{Pr}=\text { Harga ditingkat pengecer }(\mathrm{Rp} / \mathrm{kg}) \\
& \mathrm{Pf}=\text { Harga ditingkat produsen }(\mathrm{Rp} / \mathrm{Kg})
\end{array}
$$

b) Margin setiap saluran pemasaran :

$$
\mathrm{Mt}=\mathrm{M} 1+\mathrm{M} 2 \ldots \ldots .+\mathrm{Mn} \ldots \ldots \ldots . .(\text { Soekartawi, } 2002)
$$

Keterangan : Mt $=$ Margin saluran pemasaran

M1 = Margin pemasaran lembaga pemasaran ke-1

M2 = Margin pemasaran lembaga pemasaran ke-2

$\mathrm{Mn}=$ Margin pemasaran lembaga pemasaran ke-n

Keuntungan pemasasaran merupakan selisih harga yang dipasarkan ke produsen dan harga yang diberikan oleh konsumen dikurangi dengan biaya pemasaran. Untuk mengetahui keuntungan pada masing-masing lembaga pemasaran maka digunakan rumus berikut (Soekartawi, 2002) :

a) Besarnya keuntungan dari masing-masing lembaga pemasaran digunakan rumus berikut:

$$
\Pi=\mathrm{Ml}-\mathrm{TC} \ldots \ldots . . .(\text { Soekartawi, 2002) }
$$

$$
\begin{array}{ll}
\text { Keterangan : } & \Pi=\text { Keuntungan lembaga pemsaran }(\mathrm{Rp} / \mathrm{kg}) \\
& \mathrm{M}=\text { Margin lembaga pemasaran }(\mathrm{Rp} / \mathrm{kg}) \\
& \mathrm{TC}=\text { Total biaya pemasaran }(\mathrm{Rp} / \mathrm{kg})
\end{array}
$$

b) Besarnya keuntungan pemasaran dari setiap saluran pemasaran digunakan rumus berikut:

$$
\Pi t=\Pi 1+\Pi 2+\ldots \ldots . . \Pi n \ldots \ldots \ldots .(\text { Soekartawi, 2002) }
$$

$$
\begin{aligned}
\text { Keterangan }= & \Pi \mathrm{t}=\text { Keuntungan saluran pemasaran } \\
\Pi 1 & =\text { Keuntungan lembaga pemasaran ke- } 1 \\
\Pi 2 & =\text { Keuntungan lembaga pemasaran ke- } 2 \\
& \Pi n=\text { Keuntungan lembaga pemasaran ke-n }
\end{aligned}
$$

\section{b.Efesiensi Pemasaran}

Efesiensi pemasaran merupakan pembagian antara biaya pemasaran dengan nilai produk yang dinyatakan dengan persen. Untuk mengetahui efesinesi saluran pemasaran digunakan rumus berikut (Soekartawi, 2002) : 


$$
\mathrm{Ep}=\frac{B p}{N p} \times 100 \% \ldots \ldots \ldots . . .(\text { Soekartawi, 2002) }
$$

$$
\begin{aligned}
\text { Keterangan : } & \text { Ep }=\text { Efesinsi Pemasaran }(\%) \\
\mathrm{Bp} & =\text { Total Biaya Pemasaran }(\mathrm{Rp} / \mathrm{kg}) \\
\mathrm{Np} & =\text { Total nilai produk yang dipasarkan }(\mathrm{Rp} / \mathrm{kg})
\end{aligned}
$$

Kriteria: yang dipakai adalah :

Ep $<50 \%=$ Pemasaran sudah efesien

Ep $\geq 50 \%=$ Pemasaran belum efesien

\section{HASIL DAN PEMBAHASAN}

\section{Sejarah Singkat UD Salacca}

UD Salacca adalah satu usaha pengolahan buah salak yang dipimpin oleh Ilham S.E. Diresmikan pada tanggal 20 Mei 2014. Usaha Salacca beralamat di jalan Sibolga Km.11 Desa Aek Nabara Kecamatan Angkola Barat Kabupaten Tapanuli Selatan Provinsi Sumatera Utara. Dari keprihatianan terhadap petani salak, dimana saat panen raya tiba harga salak anjlok dan tidak seimbang dengan biaya produksi, sehingga membuat petani tidak bersemangat untuk memamnen salak dari batangnnya. Dengan adanya pengolahan salak ini memberikan nilai tambah pada buah salak yang melimpah serta dapat mengenalkan buah salak kepada daerah lain yang merupakan ciri khas dari Tapanuli Selatan. Namun setelah tahun 2012 UD Salacca memisahkan diri dari koperasi Agrina dan membentuk suatu usaha baru yaitu UD Salacca. Saat bekerja sama dengan koperasi Agrina UD Salacca telah menghasilkan 4 produk yaitu keripik salak, dodol salak, sirup salak, dan kurma salak. Setelah tahun 2014 UD Salacca berhasil menambah beberapa variasi produk baru yaitu agar-agar salak, kopi biji salak, kecap salak, minuman salak dan madu salak.

\section{Proses Pembuatan Produk Agroindustri Pengolahan Salak UD Salacca}

Salak yang telah diterima dari petani melalui proses pembelian kemudian dikupas kulitnya untuk segera dilakukan pensortiran dan grading berdasarkan ukuran dan kesegaran buah. Proses pengolahan salak UD Salacca masih tergolong sederhana dan semua prosesnya dikerjakan oleh tenaga kerja manusia dan alat-alat produksi yang sederhana.

1. Proses Pembuatan Kecap Salak

Pemisahan biji dilakukan salak sampai daging salak terpisah dengan bijinya menggunakan kayu. Penggilingan terhadap daging salak menggunakan mesin penggiling. Penghalusan juga dilakukan terhadap cabai rawit hijau, kemudian ditumis dalam wajan menggunakan air bersih secukupnya tanpa minyak. Lalu dimasukkan gula merah yang sudah diiris tipis-tipis sambil di aduk-aduk. Setelah itu masukkan campuran cabai dan gula merah ke dalam kuali yang berisi daging salak dan diaduk kembali dengan pelan-pelan dengan menggunakan api yang sedang. Setelah semua bahan sudah tercampur kemudian masukkan garam dan aduk kembali. Apabila sudah mendidih lalu tambahkan sari kurma. Pemasakan dilakukan dalam satu wajan besar sampai seluruh bahan tercampur.

2. Proses Pembuatan Kopi biji Salak

Biji salak yang telah disortir dicuci dengan air bersih untuk menghilangkan bagianbagian daging atau kotoran yang menempel. Kemudian dilakukan penjemuran terhadap biji salak dan di letakkan di atas nampan, diletakkan di bawah panas sinar matahari. Waktu penjemuran terhadap biji salak biasanya dilakukan selama 2 hingga 5 hari tergantung pada kondisi cuaca. Seteleh dijemur dilakukan penggongsengan biji salak dalam wajan tanpa 
minyak..Proses penggilingan biji salak melalui dua tahap penggiligan. Pertama, biji salak dihancurkan menggunakan alu dan lumping. Kemudian, setelah biji salak hancur, digiling kembali menggunakan mesin penghalus kopi, sehingga diperoleh serbuk halus biji salak atau kopi biji salak.

3. Proses Pembuatan keripik Salak

Daging salak dipisahkan dengan biji salak dengan cara daging salak di iris tipis menggunakan pisau khusus menjadi tiga bagian dan biji salak dikeluarkan dari dalam daging salak tersebut. Penggorengan dilakukan dengan memasukkan irisan salak tersebut ke dalam tabung fresto yang sudah berisi dengan minyak goreng. Setelah masak kemudian keripik tersebut ditiriskan agar tidak terlalu banyak mengandung minyak.

4. Proses Pembuatan Dodol Salak Salak

Pisahkan antara danging salak dan biji salak dengan cara dipukul menggunakan kayu. Danging salak yang kemudian direbus selama beberapa jam sampai berubah warna dan bertekstur lunak. Setelah itu ditiriskan untuk menghilangkan kandungan air yang masih tersisa. Setelah ditiriskan dihaluskan menggunakan mesin penghalus. Adonan daging salak diletakkan dalam kuali besar kemudian dicampurkan dengan adonan dari gula, tepung, dan santan. Semua bahan dicampurkan kemudian dimasak sambil diaduk-aduk selama 8 jam. Gula dicampurkan dalam tiga tahap yaitu saat pencampuran adonan, saat adonan setengah matang, dan saat keadaan matang. Setelah mengental, dodol salak di letakkan ke dalam beberapa wajan, kemudian didiamkan selama satu hari hingga mengental.

5. Proses Pembuatan Agar- agar salak

Danging salak diiris secara tipis dan memanjang. Rebus daging salak tersebut sampai lunak dan ditambahakan dengan pewarna makanan. Pada wajan yang lain masak masak nutrizel dan agar-agar powder dengan air hingga semua bahan bercampur. Setelah semua bahan tercampur dan cairan agar-agar panas tambahnkan gula, kemudian aduk-aduk lagi. Setelah semua bahan tercampur kemudia tambahahkan daging salak yang di telah direbus tadi aduk hingga bahan tercampur rata dan mengental.

6. Proses Pembuatan Kurma Salak

Buah salak direndam selama satu malam dengan menggunakan air garam. Setelah besoknya dicuci kembali dengan air bersih kemudian direbus dalam wajan tanpa memisahkan dengan bijinya. Masukkan gula ke adonan tersebut dan diaduk hingga rata. Angkat wajan dan diamkan beberapa jam setelah itu direbus lagi. Proses perebusan dilakukan sebanyak 5 kali hingga warna berubah menjadi hitam seperti warna kurma. Selanjutnya dilakukan penjemuran terhadap kurma salak tersebut selama satu hari hingga kering dan tergantung terhadap kondisi cuaca.

7. Proses Pembuatan Madu Salak

Pemisahan biji dengan daging buah salak dilakukan dengan cara dipukul. Daging buah salak selanjutnya akan melalui proses juicering dilakukan dengan tanpa air. Pemasakan sari buah salak dengan menambahkan gula dan madu sehingga diperoleh sari buah salak yang sudah tercampur dengan gula pasir dan madu. Pemasakan dikakukan pada suhu $85^{\circ} \mathrm{C}$ sehingga seluruh bahan tercampur.

8. Proses Pembuatan Minuman Salak

Pemisahan biji dengan daging buah salak dilakukan dengan cara dipukul. Selanjutnya daging salak akan melalui proses juicering dilakukan tanpa menambah air. Sari salak kemudian direbus pada suhu $100{ }^{\circ} \mathrm{C}$ dengan menambahkan gula pasir dan diaduk sehingga bahan tercampur semua. Setelah diperoleh minuman salak setengah jadi, minuman salak didinginkan kemudian disaring agar memperoleh minuman salak yang bersih tanpa serat buah. 


\section{Proses Pembuatan Sirup Salak}

Pemisahan biji dengan daging buah salak dilakukan dengan cara dipukul. Selanjutnya daging salak akan melalui proses juicering dilakukan tanpa menambah air. Juicering. Sari salak yang telah diperoleh direbus dalam dua tahapan. Yang pertama direbus pada suhu $100^{\circ} \mathrm{C}$ hingga mendidih. Setelah itu lakukan pencampuran dengan gula. Rebus kembali, kemudian didingankan.

UD Salacca menggunakan bahan baku saak dengan rata-rata 12.861pertahun $\mathrm{kg}$ pertahun menghasilkan produk olahan salak sebanyak $11.099 \mathrm{~kg}$ pertahunnya. Untuk $1 \mathrm{~kg}$ olahan salak dijual dengan rata-rata harga $\mathrm{Rp} 67.815$ per kg.

\section{Analisis Keuntungan}

Keuntungan agroindustri UD Salacca merupakan pengurangan dari total biaya yang dikeluarkan dengan hasil penjualan. Diketahui bahwa bahwa rata-rata keuntungan UD Salacca yaitu sebesar $\mathrm{Rp}$ 240.623.151,- per tahun dengan rata-rata peneriman $\mathrm{Rp}$ 780.339.000,- dan total biaya sebesar Rp 539.715.849,-- pertahun. Dapat disimpulkan bahwa total pendapatan yang diperolah lebih besar dari biaya produksi (TR>TC), hal ini menunjukkan bahwa agroindustri pengolahan salak UD Salacca menguntungkan.

\section{Kelayakan Usaha}

\section{a. Revenue Cost Ratio (R/C Ratio)}

Revenue Cost Ratio (R/C Ratio) menunjukkan perbandingan antara penerimaan dengan biaya total agroindusti UD Salacca. Diperolah bahwa perhitungan nilai Revenue Cost Ratio (R/C Ratio) pada agroindustri UD Salacca yaitu menguntungkan setiap tahunnya karena nilai $\mathrm{R} / \mathrm{C}$ ratio Rp.1,44 > 1. Artinya setiap pengeluaran Rp. 100,- memberikan penerimaan $\mathrm{Rp}$ 144,- maka agroindustri UD Salacca layak untuk di usahakan.

\section{b. Break Event Point (BEP)}

Break Event Point (BEP) merupakan keadaan dimana penerimaan UD Salacca sama dengan jumlah biaya, UD Salacca tidak memperoleh keuntungan dan tidak menderita kerugian. Diketahui bahwa rata-rata BEP produk dan BEP harga UD Salacca dari tahun 20152020 yaitu $7.074 \mathrm{~kg}$ dan Rp 48.766,-. Sedangkan rata-rata nilai produksi UD Salacca yaitu sebanyak $11.248 \mathrm{~kg}$ pertahun dengan rata-rata harga jual produk sebesar Rp 76.296,-per kg. Dapat disimpulkan bahwa jumlah produksi dan harga UD salacca lebih besar dari BEP produk dan BEP harga maka UD Salacca dikatakan menguntungkan dan layak untuk untuk dikembangkan.

\section{c. Return on Investment (ROI)}

Return on Investment (ROI) digunakan untuk mengukur seberapa besar kemampuan UD Salacca dengan seluruh dana yang ditanamkan dalam aktiva yang digunakan untuk pengoperasian perusahaan untuk meghasilkan keuntungan. Diperolah nilai rata-rata nilai return on investment (ROI) sebesar $44 \%$ per tahun.Artinya setiap biaya produksi yang dikerluarkan UD Salacca sebesar Rp 100,-, diperoleh keuntungan sebesar Rp 44,- maka agroindustri UD Salacca layak untuk di usahakan.

\section{Saluran pemasaran, Margin Pemasaran dan Efesiesi pemasaran UD Salacca}

\section{a. Saluran Pemasaran UD Salacca}

Berdasarkan hasil observasi dan wawancara dengan pihak-pihak yang terkait dengan UD Salacca diketahui ada beberapa saluran pemasaran dari UD Salacca sampai ke konsumen Saluran pemasaran UD Salacca dapat dilihat pada gambar 1. 


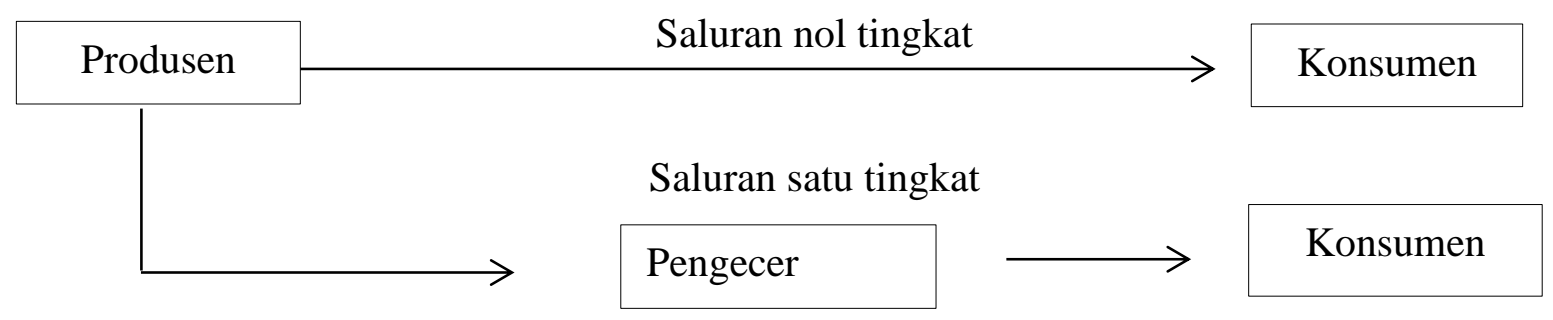

\section{Gambar 1. Saluran Pemasaran UD Salacca}

Berdasarkan Gambar 1 UD Salacca melalui beberapa saluran pemasaran yaitu:

1. Saluran Pemasaran Nol Tingkat

Saluran pemasaran ini merupakan saluran yang dilakukan langsung dari outlet UD Salacca langsung ke konsumen akhir tanpa melalui lembaga pemasaran lain. Produk yang dibeli oleh konsumen hanya beberapa produk saja sesuai dengan harga yang ditentukan oleh UD Salacca.Harga produk UD Salacca dijual Rp 76.296,- per kg langsung kepada konsumen akhir.

2. Saluran Pemasaran Satu Tingkat

Saluran pemasaran ini dalam proses pemasaran produk UD Salacca ke konsumen melalui suatu lembaga pemasaran yaitu pedagang oleh-oleh. Pedagang oleh-oleh yang membeli produk olahan UD salacca dengan jumlah banyak dan dengan harga yang lebih murah.. Harga produk UD Salacca dijual dengan harga Rp 67.815 per kg kepada pedang oleholeh kemudian pendagang oleh-oleh menjual produk UD Salacca dengan harga Rp 76.296,per kg kepada konsumen akhir.

\section{b. Margin Pemasaran, Biaya Pemasaran dan keuntungan pemsaran}

1. Margin Pemasaran

Margin pemasaran agroindustri UD Salacca merupakan selisih antara harga beli dan harga jual antara produsen dan konsumen. Untuk margin pemasaran UD Salacca dapat dilihat pada tabel 1 .

Tabel 1. Margin Pemasaran UD Salacca

\begin{tabular}{clr}
\hline $\begin{array}{c}\text { Saluran } \\
\text { Pemasaran }\end{array}$ & \multicolumn{1}{c}{$\begin{array}{c}\text { Lembaga Pemasaran dan } \\
\text { Komponen Marjin }\end{array}$} & Nilai $(\mathbf{R p} / \mathbf{K g})$ \\
\hline \multirow{3}{*}{ Saluran 1 } & UD Salacca & \\
& Biaya Produksi & 17.751 \\
& Harga jual & 76.296 \\
Margin & $\mathbf{5 8 . 5 4 5}$ \\
\hline & UD Salacca & 17.751 \\
& Biaya produksi & 67.815 \\
& Harga jual & $\mathbf{5 0 . 0 6 4}$ \\
Saluran 2 & Margin & \\
& Pengecer & 67.815 \\
& Harga beli & 76.296 \\
& Harga jual & $\mathbf{8 . 4 8 1}$ \\
\hline
\end{tabular}


Berdasarkan Tabel 1 diperoleh margin pemasaran pada saluran pemasaran I yaitu UD Salacca dengan nilai margin pemasaran yang paling tinggi yaitu Rp 58.545 ,- per $\mathrm{kg}$. Hal ini karna UD Salacca langsung menjualnya produknya kepada kosumen akhir sehingga tidak ada pengurangan harga jual produk. Pada saluran pemasaran II terdapat yaitu UD Salacca dengan margin $\mathrm{Rp} 50.545$,- per $\mathrm{kg}$ dan pengecer dengan margin $\mathrm{Rp} 8.481,-$.

2. Biaya Pemasaran dan Keuntunga Pemasaran UD Salacca

Biaya pemasaran ditanggung oleh lembaga pemasaran yang terlibat berupa biaya tenaga kerja, biaya kemasan dan biaya transportasi. Besarnya biaya pemasaran dan keuntaungan pemasaran dapat dilihat pada tabel 2.

Tabel 2. Biaya Pemasaran dan Keuntungan UD Salacca

\begin{tabular}{|c|c|c|c|c|}
\hline $\begin{array}{l}\text { Saluran } \\
\text { Pemasaran }\end{array}$ & $\begin{array}{l}\text { Lembaga } \\
\text { Pemasaran }\end{array}$ & Margin & $\begin{array}{l}\text { Biaya } \\
\text { Pemasaran } \\
(\mathrm{Rp} / \mathrm{kg})\end{array}$ & $\begin{array}{l}\text { Keuntungan } \\
\text { (Rp/kg) }\end{array}$ \\
\hline \multirow{4}{*}{ Saluran 1} & UD Salacca & & & \multirow[b]{4}{*}{31.994} \\
\hline & 1. Biaya Tenaga Kerja & & 8.431 & \\
\hline & 2. Biaya Kemasan & & 18.121 & \\
\hline & Total & 58.545 & 26.551 & \\
\hline \multirow{9}{*}{ Saluran II } & UD Salacca & & & \\
\hline & 1. Biaya Tenaga Kerja & & 8.431 & \\
\hline & 2. Biaya Kemasan & & 18.121 & \\
\hline & & 50.064 & 26.551 & 23.513 \\
\hline & Pengecer & \multirow{2}{*}{\multicolumn{3}{|c|}{1.500}} \\
\hline & 1. Biaya Tenaga Kerja & & & \\
\hline & 2. Biaya Transportasi & \multicolumn{3}{|c|}{1.000} \\
\hline & & 8.481 & 2.500 & 5.981 \\
\hline & Total & & 29.051 & 29.494 \\
\hline
\end{tabular}

Berdasarkan Tabel 2 diperoleh bahwa pada saluran pemasaran I UD Salacca menjual produknya langsung ke konsumen akhir dengan mengeluarkan beberapa biaya seperti biaya tenaga kerja sebesar Rp 8.431,- per kg dan biaya kemasan Rp 18.121,- per kg. Biaya kemasan UD Salacca lebih tinggi dari biaya tenaga kerja karna dalam proses pengemasan produk olahan salak UD Salacca menggunakan beberapa macam kemasan dan pelengkap kemasan seperti kotak karton, botol, plastik, lem kertas, solasiban dan lainnya. Pada saluran pemsaran I biaya trasportasi tidak dibutuhkan karna konsumen mendatangi langsung outlet UD Salacca. Dari biaya-biaya tersebut diperoleh bahwa dalam proses pemasaran produk UD Salacca mendapatkan keuntungan sebesar Rp 31.994,- per kg.

Pada saluran pemasaran II lembaga yang terlibat yaitu UD Salacca dan pedagang pengecer. UD Salacca mengeluarkan biaya pemasaran yang sama dengan saluran pemasaran I namun UD Salacca menjual produknya dengan harga yang lebih murah sehingga mendapatkan keuntungan lebih kecil yaitu sebesar Rp 23.513,-- per kg. Pada lembaga pemasaran pengercer terdapat beberapa biaya yang harus dikeluarkan yaitu biaya tenaga kerja sebesar Rp 1.500,- per kg dan biaya trasnportasi sebesar Rp 1.000 per $\mathrm{kg}$ sehingga pada pengecer mendapat keuntungan sebesar Rp 5.981 per kg. Biaya yang dikeluarkan pengecer tersebut merupakan biaya yang dikelurkan pada saat membeli produk langsung ke outlet UD Salacca dan kemudian menjualnya kembali pada outlet masing-masing. 


\section{c. Efesiensi Pemasaran}

Untuk mengetahui efesiensi masing-masing saluran pemasaran UD Salacca maka perlu dilihat besarnya biaya yang dikeluarkan dan harga jual disetiap lembaga pemasaran dapat dilihat pada tabel berikut:

Tabel 3. Efesiensi Pemasaran UD Salacca

\begin{tabular}{cccc}
\hline Saluran Pemasaran & $\begin{array}{c}\text { Biaya } \\
\text { Pemasaran } \\
(\mathbf{R p} / \mathbf{K g})\end{array}$ & $\begin{array}{c}\text { Harga jual } \\
(\mathbf{R p} / \mathbf{k g})\end{array}$ & $\begin{array}{c}\text { Efesiensi } \\
\text { Pemasaran }\end{array}$ \\
\hline Saluran I & 26.551 & 76.296 & $35 \%$ \\
Saluran II & 29.051 & 76.296 & $38 \%$ \\
\hline
\end{tabular}

Berdasarkan Tabel 3 efesiensi pemasaran UD Salacca dapat dilihat bahwa saluran pemasaran yang memiliki nilai efesiensi terkecil adalah saluran pemasaran I sebesar 35\% dan pada saluran pemasaran II sebesar $38 \%$ persen berdasarkan hal tersebut maka dapat disimpulkan bahwa saluran pemasaran I dan saluran pemasaran II efesien karena nilai efesiensi pemasaran dibawah $50 \%$ (Ep<50\%). Namun saluran pemasaran yang paling efesien adalah saluran pemasaran I hal ini terjadi karena persentasenya efesiensi pemasarnya lebih rendah dan biaya yang dikelurkan pada saluran pemasaran I lebih sedikit dibangdingkan saluran pemasaran II dan saluran pemasaran I mempunyai saluran pemasaran yang lebih pendek dari pada saluran pemasaran II.

\section{KESIMPULAN DAN SARAN}

\section{Kesimpulan}

Berdasarkan hasil penelitian yang sudah dilakukan diperoleh kesimpulan sebagai berikut:

1. Teknik pegolahan salak UD Salacca dimulai dari persiapan yaitu pengupasan dan pencucian buah salak hingga bersih. Kemudian proses pemisahan daging salak dengan biji. Selanjutnya proses penghalusan dengan dilakukan dengan cara direbus kemudian proses penggilngan dagiang dilakukan dengan mesin giling dan proses juisering. Pemsakan produk dilakukan sesuai dengan bahan-bahan produk yang dibutuhkan. Pengemasan produk tedapat dua jenis kemasan yaitu untuk kecap salak, madu salak, minuman salak,dan sirup salak menggunaan botol dan produk dodol salak, kurma salak, keripik salak, kopi biji salak,dan agar-agar salak menggunakan kotak karton.

2. Agroindutri pengolahan salak UD Salacca Desa Aek Nabara Kecamatan Angkola Barat Kabupaten Tapanuli Selatan Provinsi Sumatra Utara memberikan keuntungan terhadap usahanya sebesar Rp 240.263.152,- per tahunnya. Nilai Revenue Cost Ratio (R/C Ratio) sebesar 1,44, nilai BEP Produksi sebesar $7.074 \mathrm{~kg}$ dan BEP harga sebesar Rp 48.766,-dan nilai Return on Investment (ROI) sebesar $44 \%$. Sehingga dapat disimpualkan bahwa Agroindutri pengolahan salak UD Salacca Desa Aek Nabara Kecamatan Angkola Barat Kabupaten Tapanuli Selatan Provinsi Sumatra Utara menguntungkan dan layak dijalankan.

3. UD Salacca mempunyai dua saluran pemasaran yaitu: saluran pemasaran 1 yaitu UD Salacca - Konsumen akhir, dan saluran pemasaran II yaitu UD Salacca - Pengecer Konsumen akhir. Pada saluran pemasaran I mimiliki margin sebesar Rp 58.545,sedangkan pada saluran pemasaran II UD Salacca memiliki margin sebesar Rp 50.064,dan pengecer memiliki margin sebesar Rp 8.481,-Saluran pemasaran I adalah saluran pemasaran yang paling efesien dengan persentase sebesar $35 \%$. 


\section{Saran}

1. Diharapkan kepada pemilik agroindustri pengolahan salak UD Salacca agar selalu dapat dapat memenuhi besarnya kebutuhan produksi dengan tetap mengutamakan kualitas walaupaun hanya menggunakan alat yang sederhana dan mengugunakan tenaga menusia dan mempertahankan harga jual yang terjangkau sehingga selalu dapat diterima konsumen dan meningkatkan pendapatan pengusaha.

2. Bagi pemarintah sebaiknya ikut membatu dalam hal memprosikan dan memperkenalkan produk-produk olahan salak UD Salacca keluar derah karna merupakan ciri khas daerah Kabupaten Tapanuli Selatan sehingga pemasaran prduk UD Salacca tidak hanya sampai ke pedagang oleh-oleh didalam derah bahkan sampai ke luar daerah.

\section{DAFTAR PUSTAKA}

Anarsis, W. 2003. Analisis Fungsi Produksi Agribisnis Salak dan Industri Pangan olahannya. J. Pengkajian Pengembangan Teknologi Pertanian. 6:66-74

Badan Pusat Statistik. 2020. Produksi Tanaman Buah-Buahan. Badan Pusat Statistik, Indonesia

Dinas Pertanian Kab. Tapanuli Selatan. 2020. Kabupaten Tapanuli Selatan Dalam Angka 2017. Badan Pusat Statistik, Tapanuli Selatan.

Kasmir dan Jakfar. 2015. Studi Kelayakan Bisnis: Edisi Revisi. Prenada Media Grup, Jakarta

Kotler, Amstrong. 2000. Prinsip-prinsip Pemasaran, edisi keduabelas, Jilid 1. Erlangga, Jakarta.

Kusnandar, Mardikanto T, dan Wibowo A. 2010. Manejemen Agroindustri. Sebelas Maret. University Press,Surakarta.

Soekartawi. 2001a. Pengantar Agroindustri. Edisi 1. Cetakan 2. PT Raja Grafindo Persada, Jakarta.

Soekartawi. 2002b. Prinsip Dasar Manajemen Pemasaran Hasil- Hasil Pertanian Teori dan Aplikasinya. Raja Grafindo Persada, Jakarta.

Soekartawi. 2006c. Analisis Usahatani. UI Press, Jakarta.

Yustina, E.W. dan Farry, B.P. 1992. Mengenal Buah Unggul Indonesia. Penebar Swadaya, Jakarta 